\title{
Effects of MLL5 and HOXA regulated by NRP1 on radioresistance in A549
}

\author{
LIHONG SHAO $^{1,2}$, YUYU ZHANG ${ }^{1,2}$, XINKOU GONG $^{3}$, ZHUO DONG $^{1}$, WEI WEI ${ }^{1}$, \\ HONGYAN SUN ${ }^{4}$, RAN SUN ${ }^{4}$, LELE CONG $^{4}$, XIANLING CONG ${ }^{4}$ and SHUNZI JIN ${ }^{1}$
}

\author{
${ }^{1}$ National Health Commission Key Laboratory of Radiobiology, School of Public Health, Jilin University; \\ ${ }^{2}$ Department of Radiation Oncology and Therapy, Jilin Provincial Key Laboratory of Radiation Oncology and \\ Therapy, The First Hospital of Jilin University; ${ }^{3}$ Department Radiology, 2nd Hospital Affiliated to Jilin University; \\ ${ }^{4}$ Scientific Research Center, China-Japan Union Hospital of Jilin University, Changchun, Jilin 130000, P.R. China
}

Received August 7, 2020; Accepted February 2, 2021

DOI: $10.3892 / 01.2021 .12664$

\begin{abstract}
Radiotherapy is widely used in the management of lung cancer, and physicians are aware that the effect of radiotherapy is dependent on radiosensitivity. Although a series of blockers and activators targeting molecules related to radioresistance have been developed as radiation sensitizers, compensatory mechanisms or drug resistance limits their clinical efficacy. The identification of a key molecule related to lung cancer cell radioresistance or an effective molecular target is a challenging but important problem in radiation oncology. A previous study found that neuropilin 1 (NRP1) is related to radioresistance in A549 cells and is associated with VEGF, PI3K-Akt, MAPK-ERK, P38, NF- $\kappa \beta$ and TGF- $\beta$. Inhibition of NRP1 can increase the radiosensitivity of A549 cells. Therefore, NRP1 may be a molecular target for radiotherapy-sensitizing drugs in lung cancer. The present study investigated the key downstream genes of NRP1, verified their regulation and clarified their roles in regulating lung cancer radioresistance. NRP1 positively regulated the downstream homeobox genes (HOXs) HOXA6, HOXA9 and mixed lineage leukaemia 5 (MLL5) in addition to MLL5-regulated HOXA6 and HOXA9, but these genes did not regulate NRP1. MLL5, HOXA6 and HOXA9 levels were decreased in tumour tissues and positively correlated with NRP1. All of these genes were induced by ionizing radiation in vivo and in vitro. NRP1 expression was significantly lower in squamous cell carcinoma compared with that in adenocarcinoma, and lymph node
\end{abstract}

Correspondence to: Dr Shunzi Jin, National Health Commission Key Laboratory of Radiobiology, School of Public Health, Jilin University, 1163 Xinmin Street, Changchun, Jilin 130000, P.R. China E-mail: jinsz@jlu.edu.cn

Dr Xianling Cong, Scientific Research Center, China-Japan Union Hospital of Jilin University, 126 Xiantai Street, Changchun, Jilin 130000, P.R. China

E-mail: congxl@jlu.edu.cn

Key words: radioresistance, neuropilin 1, homeobox gene A, mixed lineage leukaemia 5, non-small cell lung cancer metastasis occurred more often in patients with lung cancer with high MLL5 and NRP1 expression compared with patients with low MLL5 and NRP1 expression. Collectively, these data confirmed that NRP1 is associated with MLL5 and regulates radioresistance through HOXA6 and HOXA9.

\section{Introduction}

According to the Global cancer statistics (2018) (1), which estimated the mortality rate and the prevalence of major types of cancer in 185 countries worldwide, the most commonly diagnosed cancer was lung cancer (11.6\% of the 11.8 million new cases), and the most common cause of cancer-associated death was lung cancer (18.4\% of the 9.6 million new cases). Thus, lung cancer is currently one of the most lethal cancers. In addition, $87 \%$ of all lung cancer cases are diagnosed as non-small cell lung cancer (NSCLC), which has a poor prognosis and 5-year overall survival (OS) rates are $<15 \%$ in China $(2,3)$. Radiation therapy is regarded as one of the main treatment strategies for NSCLC (1). However, enhancement of radiosensitivity is a key issue.

Neuropilin 1 (NRP1), a transmembrane receptor, is primarily found in arterial endothelial cells and plays crucial roles in tumour growth and metastasis (4-7). It appears to support the migration, proliferation and invasion of tumour cells in renal cancer, lung cancer and glioblastoma multiforme $(8,9)$. Researchers have also shown that NRP1 is important in radioresistance. Glinka et al (10) reported that overexpression of NRP1 decreases irradiation-induced apoptosis of glioma cells. Our previous study showed that knockdown of endogenous NRP1 expression enhances radiosensitivity and inhibits invasion and migration after irradiation of A549 cells both in vivo and in vitro (11). Using a bioinformatics approach based on a luciferase reporter assay, we previously demonstrated that NRP1, a putative miR-9 target, may be involved in the promotion of cancer cell migration, invasion and angiogenesis (12). An improved understanding of NRP1 signalling may enable the design of therapies to improve the radiosensitivity of NSCLC cells. Therefore, the present study mainly investigated the downstream genes regulated by NRP1 and their role in radiation. 
Homeobox genes (HOXs) are developmental genes that encode homeoproteins that function as critical master regulatory transcription factors during normal embryogenesis and anterior-posterior axis formation (13-16). These genes play an important role in different tissue types and in the development of tumours (17-19). Previous research has also demonstrated that some HOXs are associated with radioresistance (20). Chiba et al (20) proved that HOXB9 can enhance radioresistance by accelerating DNA damage responses and inducing epithelial-to-mesenchymal transition. The MLL gene is a transcriptional regulator that mainly modifies genes by H3K4-methylation (21). MLL5 is a recognized oncosuppressor gene that contains SET and PHD domains and is homologous to Drosophila TRITHORAX and yeast SET3 (22-24). Located on chromosome 7q22, MLL5 is a nuclear protein that forms speckled foci, and is also an important regulator of DNA methylation (25-27). The MLL protein has a positive regulatory effect on HOX gene expression and is mainly involved in maintaining HOX gene expression. MLL5 can regulate the cell cycle and the expression of adenovirus E2 factor-1 through host cell factor 1. Knockdown of MLL5 expression can suppress HeLa cell proliferation and arrest the cell cycle in $\mathrm{G}_{1}$ phase (28). In view of these characteristics of HOX and MLL, the present study explored their role in radiation mainly from the perspective of cell cycle progression and proliferation.

The present study identified the HOXs associated with NRP1 and radioresistance, evaluated the mechanism by which NRP1 enhances radioresistance via the HOX-dependent pathway and verified the relationship of NRP1 with the tumour radiotherapy response using clinical tissues and a nude mouse model. Thus, the results may provide valuable information for understanding the mechanisms of NSCLC pathogenesis and an opportunity to develop more effective clinical therapies.

\section{Materials and methods}

Cell lines and treatment. For transient transfection, A549 cells (The Type Culture Collection of the Chinese Academy of Sciences) were transfected with $5 \mu \mathrm{g}$ of targeted or non-targeting sequence negative control (NC) short interfering (si)RNA using Lipofectamine ${ }^{\circledR} 3000$ according to the manufacturer's instructions (Invitrogen; Thermo Fisher Scientific, Inc.). siRNAs were used to interfere with HOXA6, HOXA9 and MLL5 expression and a negative siRNA was used as the control group named si-NC. At 3 days following transfection, cells were collected and the transfection efficiency was analysed. The most efficient siRNA was selected for the subsequent experiments. The sequences used were as follows: HOXA6: 5'-CCUUGUUUCUACCAACAGU-3', HOXA9: 5-CUCCAGUUGAUAGAGAAAA-3' and MLL5: 5'-GAG ACGCACUUAUAGUCAA-3'. For stable transfection, A549 or H1299 (The Type Culture Collection of the Chinese Academy of Sciences) cells infected with short hairpin (sh)NRP1 or pLNCX2-NRP1 lentivirus were used as stable cell models for NRP1-knockdown or overexpression called -NRP1 ${ }^{\text {low }}$ or -NRP1 ${ }^{\text {high }}$ cells, respectively. The negative control cells were transfected with the lentivirus containing the plasmid backbone named NC-NRP1 ${ }^{\text {low }}$ or NC-NRP1 $1^{\text {high }}$. These stably expressed cells were produced Shanghai GenePharma Co.,
Ltd. Irradiated A549 cells (6 Gy each time, a total of five times, once every two weeks) were used as the radiation-resistant (RR) model cells, named A549-RR cells. This was termed IR1 after the first irradiation, IR2 after the second irradiation and up to the fifth exposure called IR5. Other cells were sham-irradiated or exposed to 10 Gy of ionizing radiation (IR) (A549-IR or H1299-IR). As the expression levels were similar, wild-type cells were used as the control instead of NC-NRP1 ${ }^{\text {low }}$ or NC-NRP $1^{\text {high }}$ when the transfected and irradiated cells were compared.

Irradiation. An X-ray generator (Model X-RAD320; PXi, Inc.) was used to deliver radiation at a dose rate of $1.00 \mathrm{~Gy} / \mathrm{min}$ $(220 \mathrm{kV} ; 18 \mathrm{~mA})$ for all cell and animal treatments.

RNA isolation and quantitative PCR. Total RNA was extracted from tissues of patients or mice and cells of A549 with different transfection or irradiation using TRIzol ${ }^{\circledR}$ reagent (Invitrogen; Thermo Fisher Scientific, Inc.) and reverse transcribed to generate cDNA according to the manufacturer's instructions (PrimeScript RT-PCR kit; Takara Bio, Inc.). Quantitative PCR was carried out to detect gene expression $\left(\mathrm{SYBR}^{\circledR}\right.$ Premix Ex Taq $^{\text {TM }}$ II; Takara Bio, Inc.). GAPDH was used as the internal control. PCRs were performed as follows: $95^{\circ} \mathrm{C}$, Melting under pre-denaturation for $30 \mathrm{sec} ; 95^{\circ} \mathrm{C}$ for additional $5 \mathrm{sec}$ and $60^{\circ} \mathrm{C}$ for $30 \mathrm{sec}$ (this step was repeated for 40 cycles). The primer sequences were synthesized by Sangon Biotech Co., Ltd. and were as follows: NRP1 forward, 5'-CCCCAAACCACTGAT AACTCG-3' and reverse, 5'-AGACACCATACCCAACAT TCC-3'; HOXA6 forward, 5'-TTGGATGCAGCGGATGAA-3' and reverse, 5'-AGCGGTTGAAGTGGAACTC-3'; HOXA9 forward, 5'-AGACCCTGGAACTGGAGAAA-3' and reverse, 5'-GGTTCTGGAACCAGATCTTGAC-3'; MLL5 forward, 5'-TTATATACCAGCAGCTCACATCATTCA-3' and reverse, 5'-CATTTTTGCTAATAAGGACTGATGGA-3'; GAPDH forward, 5'-ACATCGCTCAGACACCATG-3' and reverse, 5'-TGTAGTTGAGGTCAATGAAGGG-3'. All samples were normalized to the internal control, and fold-changes were calculated by relative quantification $\left(2^{-\Delta \Delta \mathrm{Cq}}\right)(29)$.

Western blot analysis and Co-immunoprecipitation. Total protein was extracted from tissues or cells and lysed using RIPA lysis buffer supplemented with $1 \mathrm{mM}$ PMSF (Sigma-Aldrich; Merck KGaA). Total protein was quantified using a bicinchoninic acid assay and $30 \mu \mathrm{g}$ protein per lane was separated via SDS-PAGE on a $10 \%$ polyacrylamide gel. Proteins were separated (Bio-Rad Laboratories, Inc.) and transferred onto polyvinylidene fluoride membranes (Merck KGaA) and blocked with 5\% BSA (B2064; Sigma-Aldrich; Merck KGaA) in TBS (RP05004V/S, Monad Biotech Co., Ltd) with $0.1 \%$ Tween-20 (Beijing Solarbio Science \& Technology Co., Ltd.) for $1 \mathrm{~h}$ at room temperature. The membranes were incubated with the designated primary antibodies against HOXA6 (1:1,000; cat. no. ab74064; Abcam), HOXA9 (1:1,000; cat. no. ab83480; Abcam), MLL5 (1:1,000; cat. no. ab75339; Abcam), NRP1 (1:1,000; cat. no. ab81321; Abcam) and GAPDH (1:1,000; cat. no. TA802519; OriGene Technologies, Inc.) overnight at $4^{\circ} \mathrm{C}$. After being washed three times in TBST buffer (10 min/wash), membranes were incubated with the corresponding goat anti-rabbit IgG H\&L (HRP) (1:5,000; 
cat. no. ab97051; Abcam) for $2 \mathrm{~h}$ at room temperature. For co-immunoprecipitation, cells were lysed in $300 \mu 1$ RIPA lysis buffer (R0278; Sigma-Aldrich; Merck KGaA), containing protease inhibitors (P8340; Sigma-Aldrich; Merck KGaA) for $30 \mathrm{~min}$ at $4^{\circ} \mathrm{C}$. Following centrifugation $\left(12,000 \mathrm{x} \mathrm{g} ; 4^{\circ} \mathrm{C}\right.$; $10 \mathrm{~min}$ ), the $1 / 10$ volume of supernatant was collected as input and analyzed using western blotting as aforementioned. The other lysates were incubated with $2 \mu \mathrm{g}$ anti-NRP1 rabbit monoclonal antibody (cat. no. ab81321; Abcam) or negative control rabbit IgG (ready to use; cat. no. A7016; Beyotime Institute of Biotechnology) stock solution at $4^{\circ} \mathrm{C}$ overnight and then rotated at $4^{\circ} \mathrm{C}$ with a mixture of protein $\mathrm{A} / \mathrm{G}$ sepharose beads ( $20 \mu \mathrm{l}$; cat. no. P2055; Beyotime Institute of Biotechnology) for $3 \mathrm{~h}$. The beads were then washed three times with RIPA buffer, and the bound proteins were boiled in 1X Laemmli buffer (cat. no. P0287; Beyotime Institute of Biotechnology) and further analysed using western blotting as aforementioned.

Cell viability assay. A549 cells (5,000 cells/well) were plated in 96-well plates after transfected with siRNAs (A549-siNC, A549-siHOXA6, A549-siHOXA9, A549-siMLL5). After irradiation, the cells were cultured for 0,24 and $48 \mathrm{~h}$ at $37^{\circ} \mathrm{C}$ in a humidified incubator containing $5 \% \mathrm{CO}_{2}$. In order to study whether HOXA6, HOXA9 and MLL5 affects cells, cell viability was determined by a MTT assay according to the manufacturer's instructions (MilliporeSigma; Merck KGaA) and quantified spectrophotometrically at a test wavelength of $570 \mathrm{~nm}$ and a reference wavelength of $630 \mathrm{~nm}$ using a microplate reader.

Cell cycle analysis and Annexin V-FITC apoptosis detection assay. Cells transfected with control RNA (A549-siNC) or siRNA (A549-siHOXA6, A549-siHOXA9 or A549-siMLL5) were cultured at $37^{\circ} \mathrm{C}$ for $24 \mathrm{~h}$ and in triplicate in six-well plates. After adherence to the wall, the cells were irradiated with $10 \mathrm{~Gy}$. For cell cycle analysis, at $24 \mathrm{~h}$ post irradiation, the cells were collected by trypsinization, washed in PBS and fixed in $70 \%$ ethanol for $30 \mathrm{~min}$ at $4^{\circ} \mathrm{C}$. The cell cycle distribution was analysed by propidium iodide staining. The cells were stained using an Annexin V-FITC Apoptosis Detection kit I (BD Biosciences) according to the manufacturer's instructions to detect apoptosis. All the cell-cycle or apoptosis data were analysed using flow cytometry (BD Bioscience) and Modfit software (version 3.3; Verity House Software).

Immunohistochemistry. The expression of NRP1 in human patients and mouse tumour tissues were examined by immunohistochemistry. The samples were fixed with $4 \%$ paraformaldehyde at room temperature overnight, dehydrated and embedded in paraffin, and cut into 5-mm thick sections. The sections were incubated at $60^{\circ} \mathrm{C}$ for $4 \mathrm{~h}$, dewaxed using xylene and rehydrated using a decreasing ethanol gradient $(100,95$, 75 and 50\%, 5 min each time). After washed three times for 5 min with PBS, sections were incubated in $3 \%$ hydrogen peroxide at room temperature for $10 \mathrm{~min}$ to inactivate endogenous peroxidase. Sections were heated at $95^{\circ} \mathrm{C}$ for $20 \mathrm{~min}$ in EDTA bufer and natural fall to room warm. The sections were blocked in 5\% BSA (B2064; Sigma-Aldrich; Merck KGaA) and $0.3 \%$ Triton X-100 (T8200; Solarbio) for $30 \mathrm{~min}$. Tissues were incubated with rabbit monoclonal human primary antibody (1:200; cat. no. ab81321; Abcam) overnight at $4^{\circ} \mathrm{C}$ and goat anti-rabbit IgG H\&L (Alexa Fluor ${ }^{\circledR}$ 647) antibody (1:200; cat. no. ab150079; Abcam) for $2 \mathrm{~h}$ at room temperature in dark. The sections were stained in $50 \mu \mathrm{l}$ DAPI solution and incubated in dark for $10 \mathrm{~min}$ at room temperature. For each slice, images of five sections were acquired under using a light microscopy and analysed using cellSens Standard 1.18 (Olympus Corporation).

Patient and tissue samples. NSCLC, adjacent non-cancerous (2-cm from the lesion) and normal tissues were collected and retrospectively analysed from 45 patients who underwent curative resection and did not receive radio- or chemotherapy before surgery, between January 2010 and December 2011 at the China-Japan Union Hospital of Jilin University (Changchun, China). Each patient had signed an informed consent prior to surgery and was informed that tissues would be used for scientific research at the time of sample collection. This study was approved by The Ethics Committee of Jilin University (Changchun, China; approval no. 2017-169).

Animals. In total, 12 severe combined immunodeficiency mice (Beijing Vital River Laboratory Animal Technology Co., Ltd.) were maintained in a specific pathogen-free facility and housed in sterile conditions, with a $12 \mathrm{~h} \mathrm{light/dark}$ cycle at $20-25^{\circ} \mathrm{C}$ and a humidity of $40-70 \%$, sterilized food and water were freely available. All experimental manipulations were undertaken in accordance with the institutional guidelines for the care and use of laboratory animals. In total, $1 \times 10^{6}$ A549 cells were directly injected into the right hind legs of mice. The present study was approved by The Ethics Committee of Jilin University (approval no. 2018-223). After 14 days, when the tumour volumes were $\sim 0.6 \mathrm{~cm}^{3}$, the tumours were irradiated with $20 \mathrm{~Gy}$. After another 14 days, the mice were sacrificed using pentobarbital sodium (intraperitoneal injection, $200 \mathrm{mg} / \mathrm{kg}$ ) or if a humane endpoint was reached; defined as a loss of $>15 \%$ of body mass, a tumour volume $>1.2 \mathrm{~cm}^{3}$, severe fever, vomiting or skin problems (wounds or signs of inflammation) or inability to ambulate or rise for food and water. No animals reached these endpoints. When the mouse stopped breathing and there was no heartbeat, the mouse was declared dead. The tumour tissues were stripped for subsequent detection. The maximum tumour size was $\sim 1.2 \mathrm{~cm}^{3}(1 \times 1 \times 1.2 \mathrm{~cm})$.

Statistical analysis. Statistical analysis was performed using SPSS 18.0 (SPSS, Inc.). The results from three independent experiments were presented as the mean \pm standard deviation values. The data of clinical specimens were expressed as median (interquartile range). The unpaired independent sample t-test or Mann-Whitney U test was used for analysis of the difference between two independent samples. One-way ANOVA, two-way ANOVA or Kruskal-Wallis test was used to compare the differences between multiple groups and Student-Newman-Keuls, Tukey's or Dunn's post hoc tests were used. The Kolmogorov-Smirnov method was used to detect the distribution of different groups. The relationship between genes and clinicopathological parameters was analysed using $\chi^{2}$ test or Fisher's exact test. The correlation analysis was 


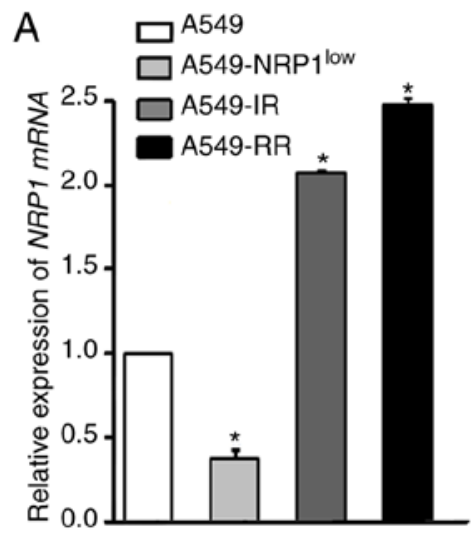

B

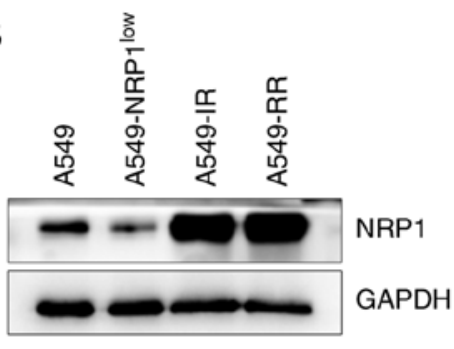

$\mathrm{F}$

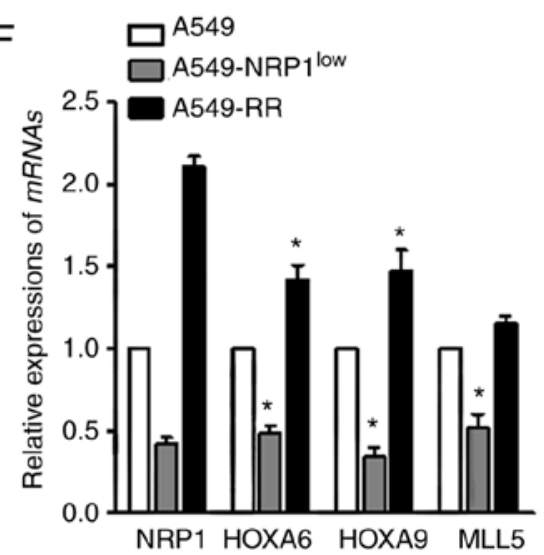

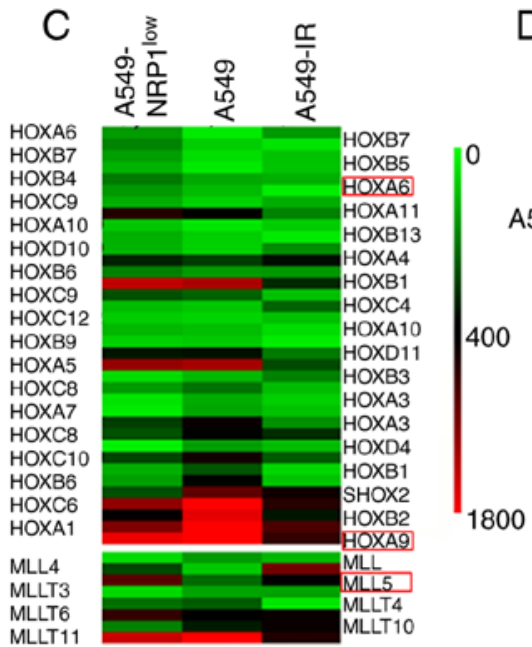

D
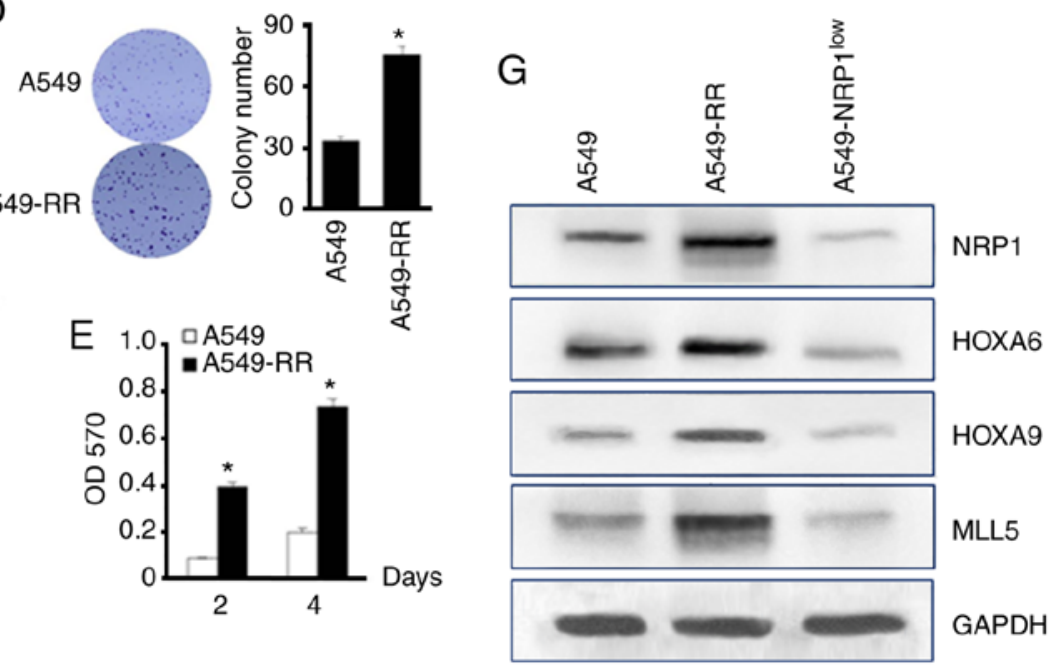

$\mathrm{H}$
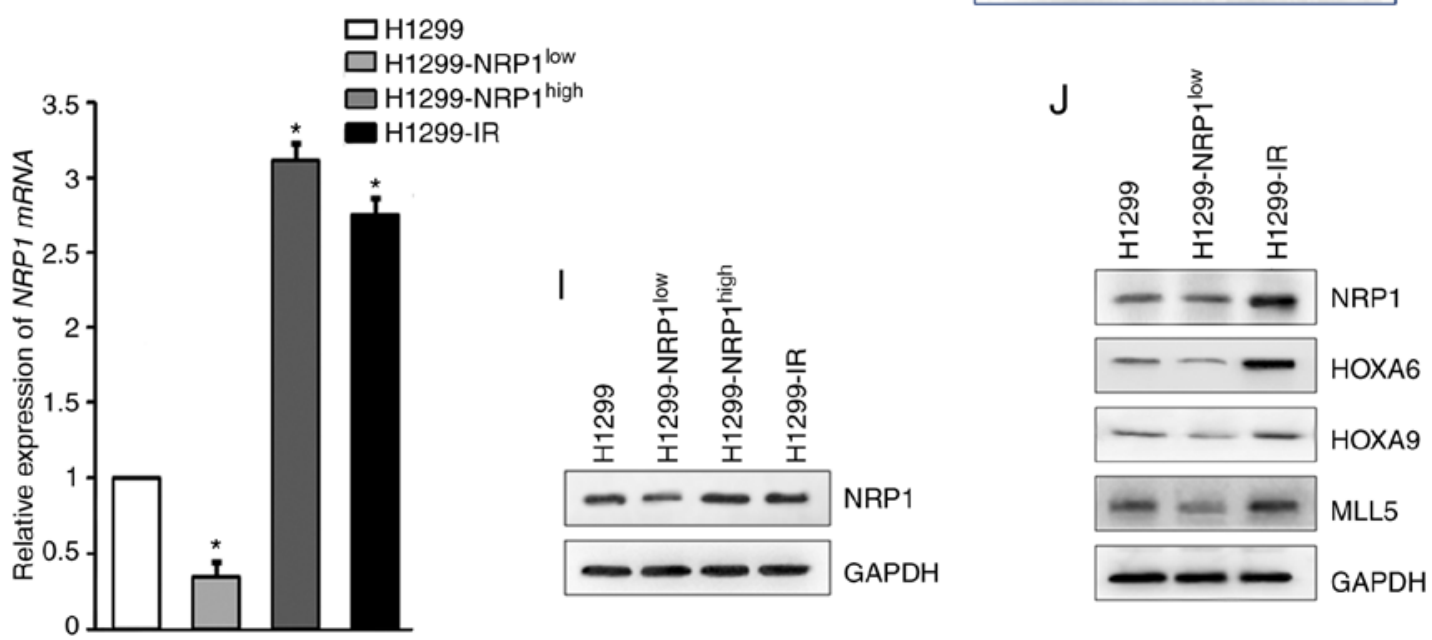

Figure 1. Expression of the key genes associated with NRP1 and irradiation. Expression of NRP1 in NRP1-knockdown A549 or irradiated A549 cells was compared with that in A549 cells using (A) qPCR and (B) western blotting. (C) Microarray analysis was performed to detect the HOX and MLL genes in the three types of cells, the boxed genes indicated the target genes selected by literature and expression analysis. (D) Colony formation assays and (E) MTT assays were used to evaluate the proliferation and viability of cells and to verify the radiation-resistant cell model. (F) mRNA and (G) protein expressions of NRP1, HOXA6, HOXA9 and MLL5 were detected using qPCR and western blotting. Expression of NRP1 in NRP1 ${ }^{\text {-low/high }}$ or irradiated H1299 cells using (H) qPCR and (I) western blotting. (J) Protein expressions of the selected genes in H1299 cell models. ${ }^{*} \mathrm{P}<0.05$ vs. untransfected A549 or H1229 cells. n=3. NRP1, neuropilin 1; qPCR, quantitative PCR; HOX, downstream homeobox gene; MLL, mixed lineage leukaemia; RR, radiation-resistant; IR, ionizing radiation.

performed using bivariate Spearman's rank correlation tests. A R-value $>0.7$ indicates a strong correlation and a R-value $<0.4$ indicates a weak correlation. P-values were selected from both sides, and $\mathrm{P}<0.05$ was considered to indicate a statistically significant difference.

\section{Results}

Screening key downstream genes of NRPl in radioresistant lung cancer cells. To identify the key genes downstream of NRP1, NRP1 was knocked down in A549 cells (A549-NRP1 ${ }^{\text {low }}$ ) 
A

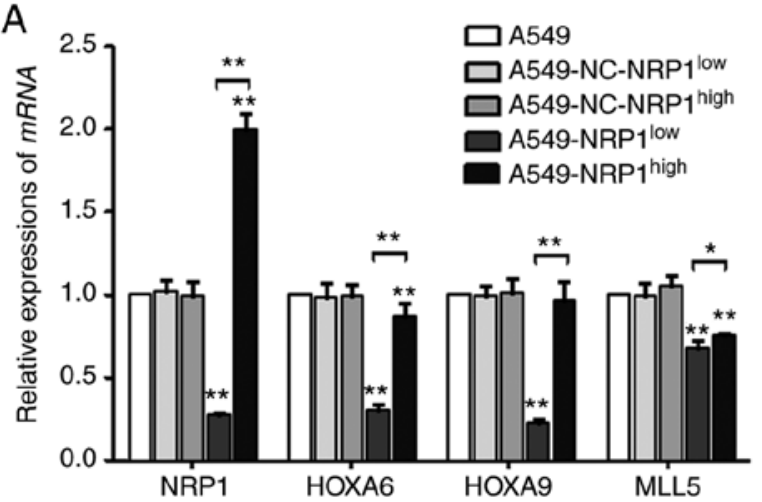

B
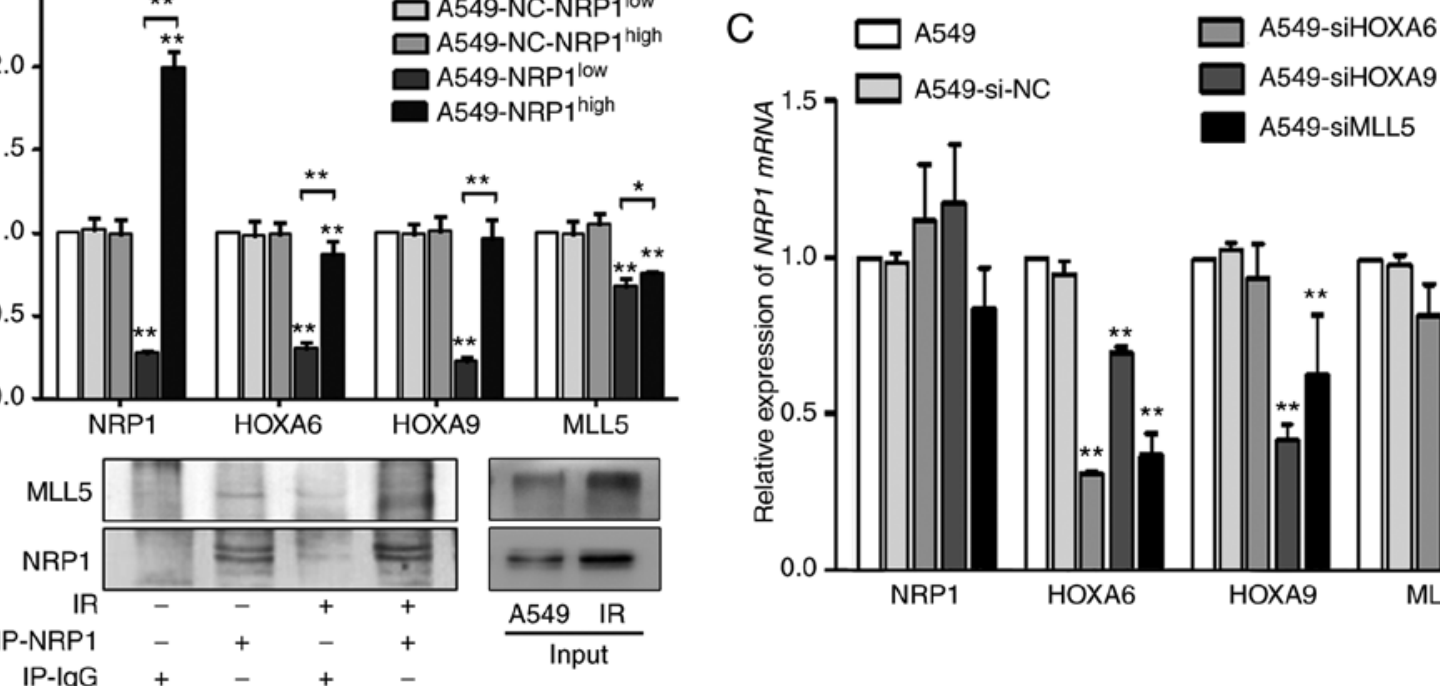

Figure 2. Interrelationships between NRP1 and its downstream genes. mRNA expression levels of NRP1, HOXA6, HOXA9 and MLL5 in cells with different NRP1 expression levels in the (A) stable transfection A549 and (C) RNA short interference groups. (B) Immunoprecipitation/western blotting of NRP1 and MLL5 in A549 cells pretreated or not pretreated with $10 \mathrm{~Gy}$ X-ray irradiation. ${ }^{*} \mathrm{P}<0.05$ and ${ }^{* *} \mathrm{P}<0.001$ vs. A459 or A549-siNC group. $\mathrm{n}=3$. NRP1, neuropilin 1; HOX, downstream homeobox gene; MLL, mixed lineage leukaemia.

or A549 cells irradiated with 10 Gy (A549-IR) (Fig. 1A and B) and then the two aforementioned types of cells and parental cells were evaluated using microarray analysis. All HOX and MLL genes were identified (Fig. 1C). Based on the literature search and verification results, HOXA6, HOXA9 and MLL5 were selected to investigate as the key genes associated with NRP1 and irradiation. To confirm these results, a radiation-resistant cell model (A549-RR) was established and on which to perform a colony formation and MTT assay to verify the success of the model (Fig. 1D and E). qPCR and western blotting results showed that the expression of NRP1 in radiation-resistant $\mathrm{A} 549$ cells was higher compared with that in wild-type A549 and similar to that in A549-IR. The mRNA and protein expression levels of these four genes are shown in Fig. 1F and G. Preliminary results showed that HOXA6, HOXA9 and MLL5 increased with the increase of NRP1 caused by irradiation and decreased with the interference of NRP1. Western blotting was used to analyse the expression of HOXA6, HOXA9 and MLL5 in H1299 cells with knocked down or overexpressed NRP1, or cells treated with 10 Gy irradiation (Fig. $1 \mathrm{H}, \mathrm{I}$ and $\mathrm{J}$ ). The results were similar to that in A549 cells, indicating that ionizing radiation can promote the expression of NRP1 and then increase the expression of HOXA6, HOXA9 and MLL5.

Relationships between NRPI and its downstream genes. A stable transfection assay was performed to change the expression NRP1 to determine the interrelationships between HOXA6, HOXA9, MLL5 and NRP1. Compared with the A549, although the expression levels of these genes were not increased in A549-NRP1 ${ }^{\text {high }}$ cells, they did decrease in A549-NRP1 ${ }^{\text {low }}$ cells (Fig. 2A). The immunoprecipitation results showed that irradiation not only upregulated NRP1 expression but also MLL5 due to their interaction (Fig. 2B). To study the interrelationships between the downstream genes and NRP1, siRNAs were used to interfere with HOXA6, HOXA9 and MLL5 expression. Compared with the A549, the mRNA expression of NRPI showed no significant change in any of the RNA interference (RNAi) groups, and MLL5 mRNA expression did not significantly change in the HOXA6 and HOXA9 RNAi groups. However, after interference with HOXA6, none of the genes were changed; after interference with $H O X A 9$, only $H O X A 6$ was significantly reduced; after interference with MLL5, HOXA6 and HOXA9 expression was significantly reduced. (Fig. $2 \mathrm{C}$ ). These results suggested that the regulatory relationship among these genes may follow the order of NRP1-MLL5-HOXA9-HOXA6.

Effect of ionizing radiation on NRPI and its downstream genes. After $10 \mathrm{~Gy} \mathrm{X}$-ray irradiation, the mRNA and protein expression levels of the four genes in were determined in A549 cells. The results showed (Fig. 3A) that the changes in MLL5 mRNA expression were associated with those of NRP1, whose expression initially decreased after irradiation but then gradually increased and was twice the original level at $48 \mathrm{~h}$ post-irradiation. There were no significant changes in the mRNA and protein expression levels of HOXA9, but HOXA6 and HOXA9 began to rise $12 \mathrm{~h}$ after irradiation. With the post-irradiation time and total dose increased during the A549-RR modelling process, the mRNA and protein expression levels of NRP1, MLL5, HOXA6 and HOXA9 increased significantly (Fig. 3B and C).

Effects of different times and doses of irradiation on the $m R N A$ and protein expression levels of NRP1 and its downstream genes in A549 cells. Cell viability in each interference group was evaluated using an MTT assay after 10 Gy X-ray irradiation (Fig. 4A). After transfection, cell viability was reduced in the HOXA9 and MLL5 interference groups but showed no obvious change in the HOXA6 group. After 

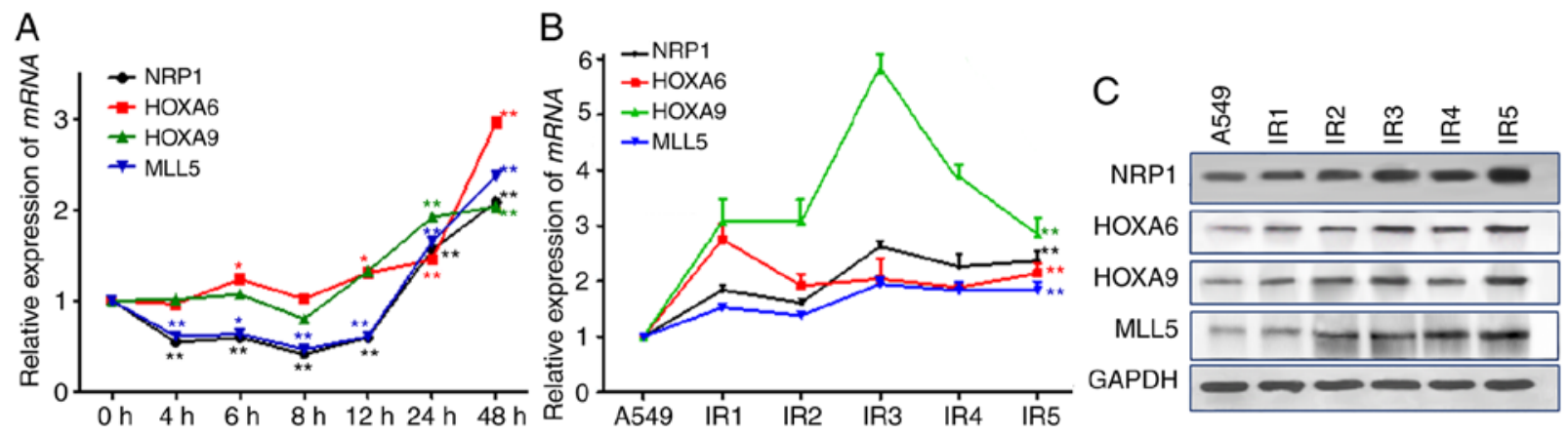

Figure 3. Expression of $N R P 1$ and its downstream genes after ionizing radiation in vitro. Quantitative PCR was carried out to detect the mRNA of the NRP1, HOXA6, HOXA9 and MLL5 at different times (A) post-irradiation and (B) in the process of establishing the A549-RR model. (C) Western blotting was performed to determine the protein levels of the four indicated genes in the process of establishing the A549-RR mode. IR1-5 refers to each irradiation treatments. ${ }^{*} \mathrm{P}<0.05$ and ${ }^{* *} \mathrm{P}<0.001$ vs. Control. $\mathrm{n}=3$. NRP1, neuropilin $1 ; \mathrm{IR}$, ionizing radiation.
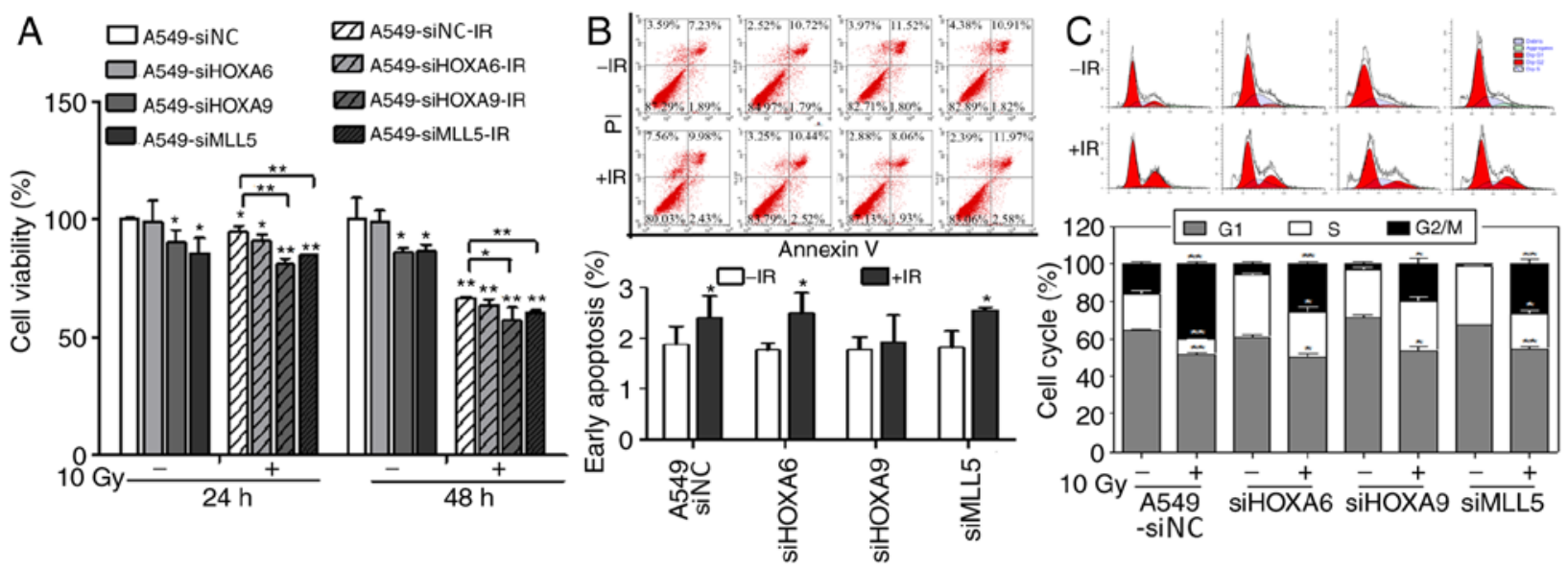

Figure 4. Effects of irradiation and HOXA6, HOXA9 and MLL5 interference in A549 cells. (A) MTT assays showed the effects of HOXA6, HOXA9 and MLL5 interference on cell viability before and after irradiation. (B) Apoptosis was evaluated using FITC/Annexin V staining, which showed the effect of gene interference on radiation-induced cell killing. (C) Flow cytometry showed the influence of gene interference on cell cycle arrest after irradiation. ${ }^{*} \mathrm{P}<0.05$ and ${ }^{* *} \mathrm{P}<0.001$ vs. A549-siNC or irradiated A549-siNC. $\mathrm{n}=3$. HOX, downstream homeobox gene; MLL, mixed lineage leukaemia; IR, ionizing radiation; si, short interfering.

irradiation, cell viability in each group decreased and was lower in the HOXA9 and MLL5 groups compared with the other groups. Apoptosis was detected using flow cytometry (Fig. 4B). siRNA-mediated interference with HOXA6, HOXA9 and MLL5 gene expression did not significantly affect the apoptosis of A549 cells. However, apoptosis was significantly increased after irradiation at $10 \mathrm{~Gy}$, whereas no significant change was seen in the HOXA9 interference group. The cell cycle distribution, as shown by flow cytometry, demonstrated that transfection significantly decreased the percentage of cells in $\mathrm{G}_{2} / \mathrm{M}$ phase and increased the percentage of cells in $\mathrm{S}$ phase. After irradiation at $10 \mathrm{~Gy}$, the percentage of cells in $G_{2} / M$ phase significantly increased and the percentage of cells in $G_{1}$ phase decreased in each interference group compared with that of the control group. However, the percentage of cells in S phase did not change in the siHOXA9 group but was significantly decreased in the other groups (Fig. 4C).

Correlations between NRPI and the selected genes in clinical samples. qPCR was used to examine the mRNA levels of NRP1-MLL5-HOXA6/HOXA9-related genes in 45 patients with NSCLC (each sample included normal, adjacent non-cancer tissues and tumour tissues). The results show that median $N R P 1$ expression level was 0.96 (quartiles: $0.68,1.41$ ) in the adjacent non-cancer tissues compared with that in normal lung tissues and was $0.14(0.06,0.27)$ in tumour tissues. The corresponding median HOXA6 expression levels were 0.73 $(0.32,1.55)$ and $0.10(0.04,0.52)$. The corresponding median HOXA9 expression levels were $0.77(0.35,1.52)$ and $0.24(0.09$, $0.13)$, and those of $M L L 5$ were $0.95(0.44,1.50)$ and $0.10(0.04$, $0.34)$. The expression level of each of the four genes in tumour tissues was significantly lower $(\mathrm{P}<0.001)$ compared with that in normal and adjacent non-cancer tissues (Fig. 5A-D). Western blotting was carried out to evaluate the protein expression of these four mediators (Fig. 5E) and the results were similar to those observed for mRNA expression that the four proteins were lower in tumour tissues compared with in normal and adjacent non-cancer tissues. Immunohistochemical staining was used to detect NRP1 protein expression in clinical tissues, and the results showed that NRP1 was significantly lower in tumour tissues compared with that in normal and adjacent non-cancer tissues (Fig. 5F). In conclusion, the expression level of NRP1, MLL5, HOXA6 and HOXA9 in tumour tissues 

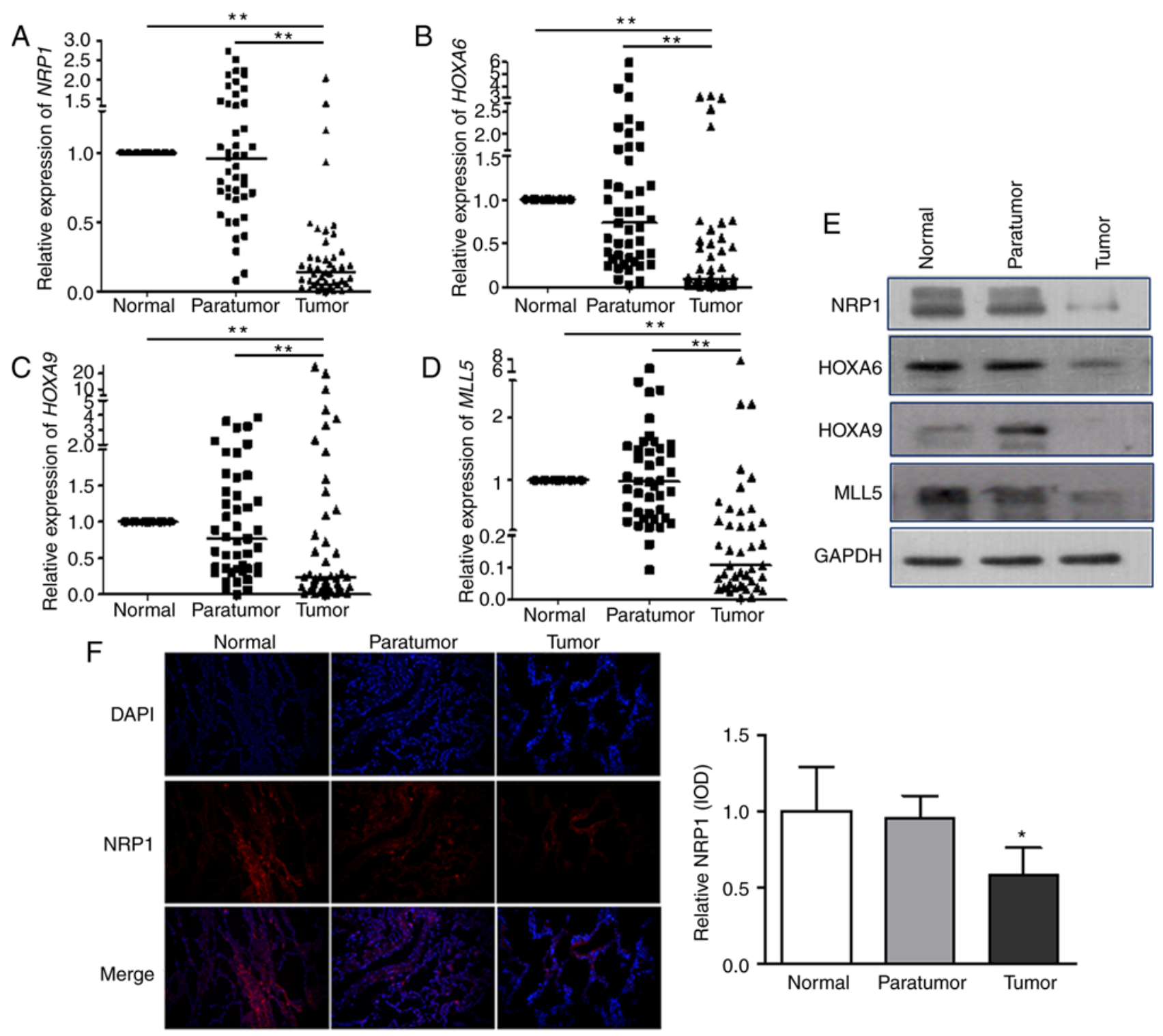

Figure 5. Expression of NRP1 and the selected genes in clinical samples. mRNA levels of (A) NRP1, (B) HOXA6, (C) HOXA9 and (D) MLL5 and (E) the corresponding protein levels were measured using quantitative PCR and western blotting in non-small cell lung cancer tissues, paired adjacent non-cancerous tissues and normal tissues from 45 patients. (F) Protein level of NRP1 was also evaluated by immunohistochemistry. ${ }^{*} \mathrm{P}<0.05$, ${ }^{* *} \mathrm{P}<0.001$ vs. normal tissues. NRP1, neuropilin 1; HOX, downstream homeobox gene; MLL, mixed lineage leukaemia; IOD, integrated optical density.

was significantly lower compared with that in normal tissues and adjacent tissues.

Correlation analysis was performed according to age, sex, clinical stage, differentiation and pathological classification (Tables I and II), and the results showed that NRP1 expression was significantly lower in squamous cell carcinoma compared with adenocarcinoma $(\mathrm{P}<0.01)$ and that patients with high expression of NRP1 and MLL5 were more likely to have lymph node metastasis compared with patients with low expression of NRP1 and MLL5 $(\mathrm{P}<0.05)$. The expression levels of these genes in para-cancerous tissues and of other genes in tumour tissues were not significantly correlated with clinicopathological characteristics.

Correlation analysis between NRP1 and HOXA6, HOXA9 or MLL5 in 45 sets of samples (Table III) showed that HOXA6, HOXA9 and MLL5 were correlated with NRP1 particularly MLL5 ( $\mathrm{R}=0.792)$, which was strongly correlated with NRP1 in both para-cancerous and tumour tissues in patients with different clinical classifications.

Effect of radiation on NRPI and its downstream genes in vivo. Take the tumor tissues of tumor-bearing mice 14 days after irradiating the tumor site and detected their expressions. The mRNA and protein expression levels of NRP1, HOXA6, HOXA9 and MLL5 increased after irradiation, and the tumour volumes decreased (Fig. 6A and B). The expression of NRP1 in tumour tissues, detected using immunohistochemistry, also significantly increased after irradiation.

\section{Discussion}

The majority of patients with NSCLC are unsuitable for surgery when diagnosed and are mainly treated with radiotherapy-based comprehensive treatment or 
Table I. Expression of NRP1 and the patient clinicopathological characteristics.

\begin{tabular}{|c|c|c|c|c|c|}
\hline Characteristic & Value, $\mathrm{n}$ & $\begin{array}{l}\text { NP-NRP1, median } \\
\quad(\mathrm{P} 25, \mathrm{P} 75)\end{array}$ & P-value & $\begin{array}{l}\text { NT-NRP1, median } \\
\quad(\mathrm{P} 25, \mathrm{P} 75)\end{array}$ & P-value \\
\hline Age, years & & & $0.466^{\mathrm{a}}$ & & 0.945 \\
\hline$<60$ & 27 & $0.98(0.73,1.43)$ & & $0.14(0.07,0.25)$ & \\
\hline$\geq 60$ & 18 & $0.89(0.54,1.48)$ & & $0.15(0.04,0.44)$ & \\
\hline Sex & & & $0.715^{\mathrm{a}}$ & & 0.825 \\
\hline Male & 31 & $0.98(0.72,1.31)$ & & $0.13(0.07,0.29)$ & \\
\hline Female & 14 & $0.80(0.63,1.84)$ & & $0.20(0.03,0.60)$ & \\
\hline Histological subtype & & & $0.404^{\mathrm{a}}$ & & $0.008^{\mathrm{a}, \mathrm{b}}$ \\
\hline Squamous cell carcinoma & 22 & $0.84(0.52,1.49)$ & & $0.08(0.04,1.49)$ & \\
\hline Adenocarcinoma & 23 & $1.00(0.73,1.43)$ & & $0.24(0.13,0.49)$ & \\
\hline Differentiation & & & 0.378 & & 0.378 \\
\hline Low & 13 & $0.90(0.74,1.20)$ & & $0.13(0.02,0.37)$ & \\
\hline Middle & 31 & $0.96(0.55,1.75)$ & & $0.17(0.07,0.36)$ & \\
\hline High & 1 & $2.22^{\mathrm{c}}$ & & 0.06 & \\
\hline Lymph node metastasis & & & $0.250^{\mathrm{a}}$ & & $0.041^{\mathrm{b}}$ \\
\hline Positive & 26 & $0.88(0.70,1.99)$ & & $0.18(0.08,0.42)$ & \\
\hline Negative & 19 & $0.98(0.55,1.17)$ & & $0.08(0.03,0.19)$ & \\
\hline Clinical stage & & & $0.541^{\mathrm{a}}$ & & 0.083 \\
\hline I & 19 & $0.98(0.55,1.17)$ & & $0.08(0.03,0.19)$ & \\
\hline II & 15 & $1.04(0.66,1.95)$ & & $0.17(0.07,0.29)$ & \\
\hline III & 11 & $0.86(0.72,2.11)$ & & $0.25(0.13,0.49)$ & \\
\hline
\end{tabular}

${ }^{a}$ Normally distributed variables analysed using t-tests or ANOVA. ${ }^{b} \mathrm{P}<0.05$. NP, the expression of genes in peritumoral tissue compared with non-cancerous lung tissue. ${ }^{\mathrm{c}}$ No interquartile range data. NT, the expression in tumour tissue compared with non-cancerous tissue. Remaining data were analysed using a Kruskal-Wallis test.

A

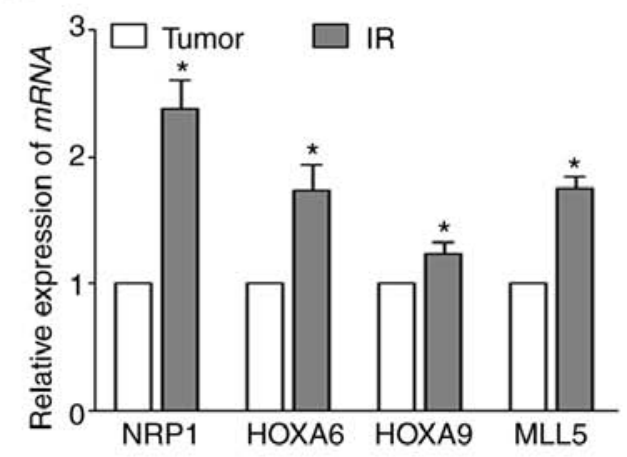

B

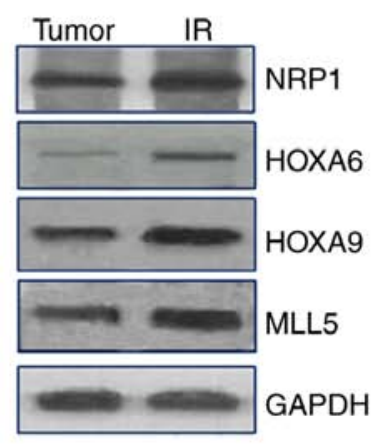

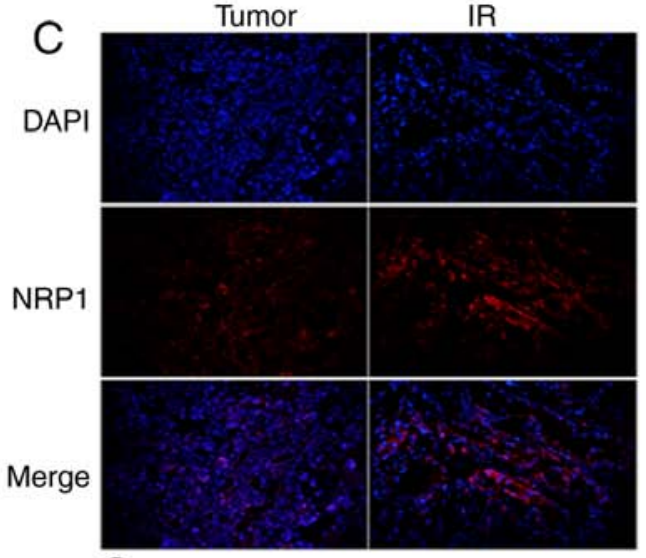

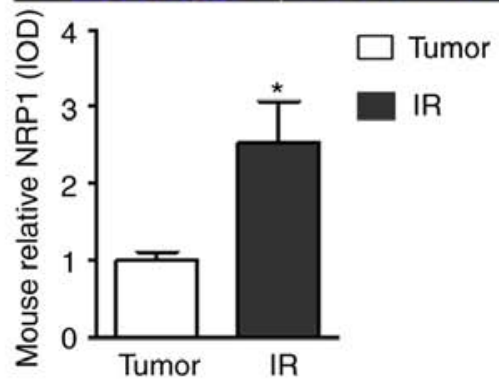

Figure 6. Expression of NRP1 and its downstream genes after ionizing radiation in vivo. (A) mRNA and (B) protein expression levels of NRP1, HOXA6, HOXA9 and MLL5 in the tumour-bearing mouse model were evaluated before and after irradiation. (C) Expression of NRP1 in tumour tissues was also detected by immunohistochemistry. (D) Image of the isolated xenografts from animals. $\mathrm{n}=5$. * $\mathrm{P}<0.05$ vs. tumour. NRP1, neuropilin 1 ; HOX, downstream homeobox gene; MLL, mixed lineage leukaemia; IR, ionizing radiation; IOD, integrated optical density. 


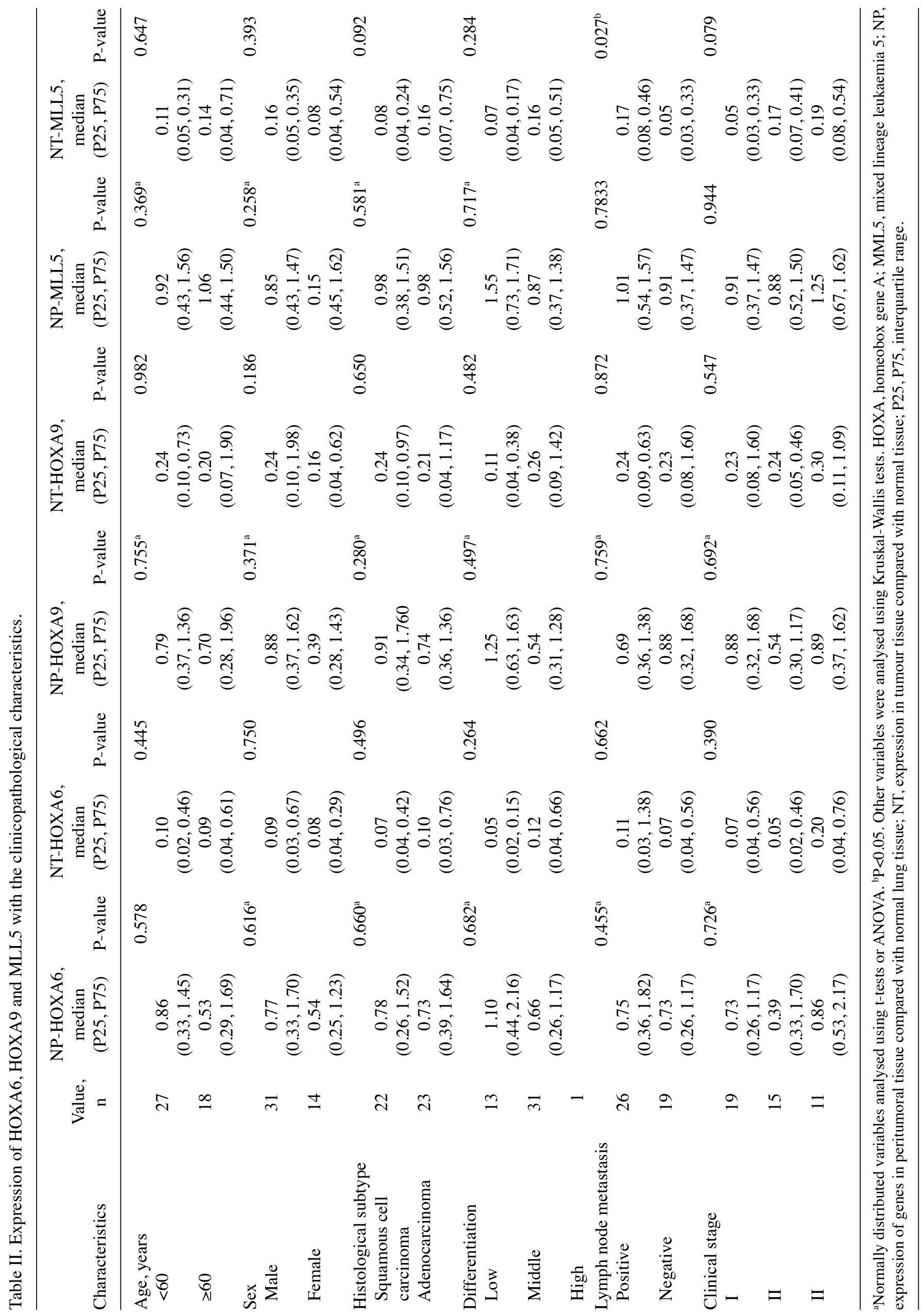


Table III. Correlation coefficient values between NRP1 and MLL5-HOXA6/HOXA9.

\begin{tabular}{|c|c|c|c|c|c|c|c|}
\hline \multirow[b]{2}{*}{ Characteristics } & \multirow{2}{*}{$\begin{array}{c}\text { Value, } \\
\mathrm{n}\end{array}$} & \multicolumn{6}{|c|}{ Correlation coefficient } \\
\hline & & NP-HOXA6 & NT-HOX A6 & NP-HOXA9 & NT-HOXA9 & NP-MLL5 & NT-MLL5 \\
\hline All dates & & 0.760 & 0.359 & 0.477 & 0.434 & 0.734 & 0.792 \\
\hline \multicolumn{8}{|l|}{ Age, years } \\
\hline$<60$ & 27 & 0.689 & 0.308 & 0.499 & 0.291 & 0.636 & 0.642 \\
\hline$\geq 60$ & 18 & 0.860 & 0.486 & 0.377 & 0.651 & 0.853 & 0.917 \\
\hline \multicolumn{8}{|l|}{ Sex } \\
\hline Male & 31 & 0.749 & 0.454 & 0.500 & 0.436 & 0.729 & 0.839 \\
\hline Female & 14 & 0.780 & 0.125 & 0.495 & 0.459 & 0.802 & 0.811 \\
\hline \multicolumn{8}{|l|}{ Histological subtype } \\
\hline Squamous cell carcinoma & 22 & 0.915 & 0.352 & 0.647 & 0.401 & 0.798 & 0.731 \\
\hline Adenocarcinoma & 23 & 0.481 & 0.458 & 0.328 & 0.602 & 0.650 & 0.775 \\
\hline \multicolumn{8}{|l|}{ Differentiation } \\
\hline Low & 13 & 0.709 & 0.088 & 0.462 & 0.319 & 0.773 & 0.645 \\
\hline Middle & 31 & 0.788 & 0.480 & 0.523 & 0.458 & 0.804 & 0.875 \\
\hline High & 1 & & & & & & \\
\hline \multicolumn{8}{|l|}{ Lymph node metastasis } \\
\hline Positive & 26 & 0.721 & 0.319 & 0.515 & 0.207 & 0.630 & 0.762 \\
\hline Negative & 19 & 0.774 & 0.463 & 0.393 & 0.804 & 0.860 & 0.659 \\
\hline \multicolumn{8}{|l|}{ Clinical stage } \\
\hline I & 19 & 0.774 & 0.463 & 0.393 & 0.804 & 0.860 & 0.659 \\
\hline II & 15 & 0.814 & 0.254 & 0.693 & 0.096 & 0.710 & 0.859 \\
\hline III & 11 & 0.582 & 0.273 & 0.245 & 0.327 & 0.503 & 0.491 \\
\hline
\end{tabular}

NP, correlation of relative expressions between NRP1 and the target gene in paracancer tissue; NT, correlation of relative expressions between NRP1 and the target gene in tumour tissue; HOXA, homeobox gene A; MML5, mixed lineage leukaemia 5; NRP1, neuropilin 1.

radiotherapy alone. The sensitivity of cells to ionizing radiation determines the efficacy of radiotherapy, and the inherent radioresistant ability of tumour cells further limits the use of radiotherapy (3). NRP1 can enhance the radiation resistance of tumours $(8,9,30,31)$. Previous studies have shown that the expression of NRP1 significantly increases with increasing radiation dose. The radiosensitivity of A549 cells overexpressing NRP1 is significantly lower compared with that of cells with NRP1 interference, therefore targeted inhibition of NRP1 increases the radiosensitivity of A549 cells $(10,13)$. The present study aimed to investigate how NRP1 enhanced radiation resistance.

To explore the interaction between NRP1 and its downstream genes, the present study established an A549 radiation-resistant cell model with high expression of NRP1 and an A549-NRP1 $1^{\text {low }}$ cell model with low expression of NRP1. Through gene microarray screening and verification using qPCR, the HOXA6, HOXA9 and MLL5 genes were selected as key downstream genes of NRP1. The results showed that the expression levels of HOXA6, HOXA9, and MLL5 were decreased after knockdown of NRP1 and increased in radiation-resistant cells as well as in NRP1-overexpressing cells. To explore this relationship, HOXA6, HOXA9 and MLL5 expressions were interfered with. siMLL5 reduced HOXA6 and HOXA9 expression, but when HOXA6 and HOXA9 were knocked down MLL5 expression did not change. Similarly, siHOXA9 transfection downregulated HOXA6, but HOXA9 expression did not change after siHOXA6 transfection. These results suggested that the regulatory relationship among these genes may follow the order of NRP1-MLL5-HOXA9-HOXA6.

To study the regulation of NRP1 and its downstream genes by ionizing radiation, the genes were examined $48 \mathrm{~h}$ after exposure. The expression of NRP1 and MLL5 initially decreased after irradiation and then began to rise $24 \mathrm{~h}$ post irradiation. During the course of establishing the radiationresistant cell model, the expression levels of each gene gradually increased with irradiation time and cumulative dose.

Then, the effects of NRP1 and its downstream genes on the radiation sensitivity of A549 cells was investigated. MTT analysis showed that the viability significantly decreased after HOXA9 or MLL5 interference, but no obvious change was observed after HOXA6 interference. These results demonstrated that the HOXA9 and MLL5 genes have a major impact on cell proliferation. The apoptosis rate was significantly increased after ionizing radiation in the wild-type, HOXA6 interference and MLL5 interference groups, but the apoptosis rate did not significantly change after HOXA9 interference. HOXA9 interference suppressed apoptosis induced by ionizing radiation, which indicated that HOXA9 may be radiation-sensitive. 
Sensitivity to ionizing radiation is different in each phase of the cell cycle; the radiosensitivity of cells in $\mathrm{S}$ phase is lower compared with that of cells in $\mathrm{G}_{1}$ phase, and the sensitivity of cells in $\mathrm{G}_{2} / \mathrm{M}$ phase is highest. Ionizing radiation can significantly arrest cells in $\mathrm{G}_{2} / \mathrm{M}$ phase $(32,33)$. The results of the present study showed that the percentage of $\mathrm{G}_{2} / \mathrm{M}$ phase cells was significantly decreased after interference with HOXA6, HOXA9 and MLL5 expression. After irradiation at $10 \mathrm{~Gy}$, the percentages of $\mathrm{G}_{2} / \mathrm{M}$ phase cells in these groups increased but were significantly lower compared with that among wild-type A549 cells. In addition, the percentage of cells in $\mathrm{S}$ phase decreased after irradiation, but the percentage of $\mathrm{S}$ phase cells among siHOXA9-treated cells did not change, which may be one of the reasons for the increase in apoptosis after irradiation. The specific molecular mechanism involved in this process requires further research. In conclusion, NRP1 can affect radiation resistance by positively regulating MLL5-HOXA6/HOXA9, and HOXA9 may affect radiation sensitivity by inducing $\mathrm{G}_{2} / \mathrm{M}$ phase arrest.

To study the relationships between NRP1, HOXA6, HOXA9 and MLL5, the expression levels of these four genes in normal, para-cancerous, and tumour tissues from 45 patients with lung cancer were determined. The results showed that the mRNA and protein expression levels of these four genes in tumour tissues were significantly lower compared with those in normal and adjacent tissues. Correlation analysis between gene expression and age, sex, clinical stage, differentiation and pathological classification showed that the expression of NRP1 in squamous cell carcinoma was significantly lower compared with that in adenocarcinoma, patients with relatively high expression of NRP1 and MLL5 were more prone to lymph node metastasis compared with those with relatively low expression, and the expression of HOXA6 and HOXA9 in tumour tissues and NRP1, HOXA6, HOXA9 and MLL5 in para-cancerous tissues were not significantly correlated with age, sex, clinical stage, differentiation degree or pathological type. In correlation analysis, coefficients with values close to 1 indicate strong correlations. A R-value $>0.7$ indicates a strong correlation and a R-value $<0.4$ indicates a weak correlation. Correlation analysis of these four genes in para-cancerous and tumour tissues showed that NRP1 was associated with the HOXA6, HOXA9 and MLL5 genes, especially with the HOXA6 and MLL5 genes in para-cancerous tissues and with MLL5 in tumour tissues.

Most patients in the present study underwent preoperative radiotherapy or chemotherapy, so collection of histopathological specimens is limited. Therefore, the study used a nude mouse tumour model to verify changes in the NRP1-MLL5-HOXA6/HOXA9 pathway after radiotherapy. The mRNA and protein expression levels ofNRP1, MLL5, HOXA6 and HOXA9 were increased after irradiation, which was consistent with the results in A549 cells. It was hypothesised that the NRP1-MLL5-HOXA6/HOXA9 pathway plays an important role in lung adenocarcinoma A549 cells both in vivo and in vitro.

In summary, NRP1 positively regulates the downstream gene MLL5, thereby affecting the expression of HOXA6 and HOXA9 in A549 cells in vitro. Ionizing radiation promotes gene expression in the NRP1-MLL5-HOXA6/HOXA9 pathway in vitro and in vivo. The expression levels of NRP1,
HOXA6, HOXA9 and MLL5 in patient tumour tissues were significantly lower compared with those in normal and adjacent tissues. The expression level of NRP1 in squamous cell carcinoma was lower compared with that in adenocarcinoma, and patients with high NRP1 and MLL5 expression levels were more prone to lymph node metastasis compared with those with low NRP1 and MLL5 expression levels.

\section{Acknowledgements}

Not applicable.

\section{Funding}

The present study was supported by grants from the National Natural Science Foundation of China (grant nos. 81573085 and 81872550).

\section{Availability of data and materials}

The datasets used and/or analysed during the current study are available from the corresponding author on reasonable request.

\section{Authors' contributions}

The study was designed by SJ and XC. Experiments were performed by LS, YZ, XG, ZD and HS. WW, LC and RS analysed and interpreted the data. LS drafted the manuscript. All authors read and approved the final manuscript.

\section{Ethics approval and consent to participate}

Each patient had signed an informed consent prior to surgery and was informed that tissues would be used for scientific research at the time of sample collection. The patient tissues study was approved by The Ethics Committee of Jilin University (approval no. 2017-169). The animal studies were approved by The Ethics Committee of Jilin University (approval no. 2018-223).

\section{Patient consent for publication}

Not applicable.

\section{Competing interests}

The authors declare that they have no competing interests.

\section{References}

1. Bray F, Ferlay J, Soerjomataram I, Siegel RL, Torre LA and Jemal A: A Global cancer statistics 2018: GLOBOCAN estimates of incidence and mortality worldwide for 36 cancers in 185 countries. CA Cancer J Clin 68: 394-424, 2018.

2. Mou J, Hu T, Wang Z, Chen W, Wang Y and Zhang W: ATM gene polymorphisms are associated with poor prognosis of non-small cell lung cancer receiving radiation therapy. Aging (Albany NY) 12: 7465-7479, 2020.

3. Zhou R, Xu T, Nguyen QN, Liu Y, Yang J, Komaki R, Gomez DR and Liao Z: Radiation dose, local disease progression, and overall survival in patients with inoperable non-small cell lung cancer after concurrent chemoradiation therapy. Int J Radiat Oncol Biol Phys 100: 452-461, 2018. 
4. Nasarre C, Roth M, Jacob L, Roth L, Koncina E, Thien A, Labourdette G, Poulet P, Hubert P, Crémel G, et al: Peptide-based interference of the transmembrane domain of neuropilin-1 inhibits glioma growth in vivo. Oncogene 29: 2381-2392, 2010.

5. Roth L, Nasarre C, Dirrig-Grosch S, Aunis D, Crémel G, Hubert $\mathrm{P}$ and Bagnard D: Transmembrane domain interactions control biological functions of neuropilin-1. Mol Biol Cell 19: 646-654, 2008.

6. Nakamura F and Goshima Y: Structural and functional relation of neuropilins. Adv Exp Med Biol 515: 55-69, 2002.

7. Giordano S, Corso S, Conrotto P, Artigiani S, Gilestro G, Barberis D, Tamagnone L and Comoglio PM: The semaphorin 4D receptor controls invasive growth by coupling with Met. Nat Cell Biol 4: 720-724, 2002.

8. Hong TM, Chen YL, Wu YY, Yuan A, Chao YC, Chung YC, Wu MH, Yang SC, Pan SH, Shih JY, et al: Targeting neuropilin 1 as an antitumor strategy in lung cancer. Clin Cancer Res 13 4759-4768, 2007.

9. Osada H, Tokunaga T, Nishi M, Hatanaka H, Abe Y, Tsugu A, Kijima H, Yamazaki H, Ueyama $Y$ and Nakamura $M$ : Overexpression of the neuropilin 1 (NRP1) gene correlated with poor prognosis in human glioma. Anticancer Res 24: 547-552, 2004.

10. Glinka Y, Mohammed N, Subramaniam V, Jothy S and Prud'homme GJ: Neuropilin-1 is expressed by breast cancer stem-like cells and is linked to NF- $\mathrm{BB}$ activation and tumor sphere formation. Biochem Biophys Res Commun 425: 775-780, 2012.

11. Dong JC, Gao H, Zuo SY, Zhang HQ, Zhao G, Sun SL, Han HL, Jin LL, Shao LH, Wei W and Jin SZ: Neuropilin 1 expression correlates with the radio-resistance of human non-small-cell lung cancer cells. J Cell Mol Med 19: 2286-2295, 2015.

12. Xiong K, Shao LH, Zhang HQ, Jin L, Wei W, Dong Z, Zhu YQ, Wu N, Jin SZ and Xue LX: MicroRNA-9 functions as a tumor suppressor and enhances radio-sensitivity in radio-resistant A549 cells by targeting neuropilin 1 . Oncol Lett 15: 2863-2870, 2018.

13. Gorski DH and Walsh K: The role of homeobox genes in vascular remodeling and angiogenesis. Circ Res 87: 865-872, 2000.

14. Kappen C: Developmental patterning as a quantitative trait: Genetic modulation of the Hoxb6 mutant skeletal phenotype. PLoS One 11: e0146019, 2016.

15. Denans N, Iimura T and Pourquie O: Hox genes control vertebrate body elongation by collinear Wnt repression. Elife 4 e04379, 2015.

16. Paço A, Aparecida de Bessa Garcia S, Leitão Castro J, Costa-Pinto AR and Freitas R: Roles of the HOX proteins in cancer invasion and metastasis. Cancers (Basel) 13: 10, 2020.

17. Morgan R, Simpson G, Gray S, Gillett C, Tabi Z, Spicer J, Harrington KJ and Pandha HS: HOX transcription factors are potential targets and markers in malignant mesothelioma. BMC Cancer 16: 85, 2016.

18. Steger J, Füller E, Garcia-Cuellar MP, Hetzner K and Slany RK: Insulin-like growth factor 1 is a direct HOXA9 target important for hematopoietic transformation. Leukemia 29: 901-908, 2015.

19. Larsen BM, Hrycaj SM, Newman M, Li Y and Wellik DM Mesenchymal Hox6 function is required for mouse pancreatic endocrine cell differentiation. Development 142: 3859-3868, 2015.
20. Chiba N, Comaills V, Shiotani B, Takahashi F, Shimada T, Tajima K, Winokur D, Hayashida T, Willers H, Brachtel E, et al: Homeobox B9 induces epithelial-to-mesenchymal transitionassociated radioresistance by accelerating DNA damage responses. Proc Natl Acad Sci USA 109: 2760-2765, 2012.

21. Slany RK: MLL fusion proteins and transcriptional control. Biochim Biophys Acta Gene Regul Mech 1863: 194503, 2020.

22. Cheng F, Liu J, Zhou SH, Wang XN, Chew JF and Deng LW: RNA interference against mixed lineage leukemia 5 resulted in cell cycle arrest. Int J Biochem Cell Biol 40: 2472-2481, 2008.

23. Emerling BM, Bonifas J, Kratz CP, Donovan S, Taylor BR, Green ED, Le Beau MM and Shannon KM: MLL5, a homolog of Drosophila trithorax located within a segment of chromosome band 7q22 implicated in myeloid leukemia. Oncogene 21: 4849-4854, 2002.

24. Lee KH, Kim BC, Jeong CW, Ku JH, Kim HH and Kwak C: MLL5, a histone modifying enzyme, regulates androgen receptor activity in prostate cancer cells by recruiting co-regulators, HCF1 and SET1. BMB Rep 53: 634-639, 2020.

25. Madan V, Madan B, Brykczynska U, Zilbermann F, Hogeveen K, Döhner K, Döhner H, Weber O, Blum C, Rodewald HR, et al: Impaired function of primitive hematopoietic cells in mice lacking the Mixed-Lineage-Leukemia homolog MLL5. Blood 113: 1444-1454, 2009.

26. Heuser M, Yap DB, Leung M, de Algara TR, Tafech A, McKinney S, Dixon J, Thresher R, Colledge B, Carlton M, et al: Loss of MLL5 results in pleiotropic hematopoietic defects, reduced neutrophil immune function, and extreme sensitivity to DNA demethylation. Blood 113: 1432-1443, 2009.

27. Milne TA: MLL5 expression as a biomarker for DNA hypermethylation and sensitivity to epigenetic therapy. Haematologica 99: 1405-1407, 2014

28. Zhou P, Wang Z, Yuan X, Zhou C, Liu L, Wan X, Zhang F, Ding X, Wang C, Xiong S, et al: Mixed lineage leukemia 5 (MLL5) protein regulates cell cycle progression and E2F1-responsive gene expression via association with host cell factor-1 (HCF-1). J Biol Chem 288: 17532-17543, 2013.

29. Livak KJ and Schmittgen TD: Analysis of relative gene expression data using real-time quantitative PCR and the 2(-Delta Delta C(T)) method. Methods 25: 402-408, 2001.

30. Yan Y, Greer PM, Cao PT, Kolb RH and Cowan KH: RAC1 GTPase plays an important role in gamma-irradiation induced G2/M checkpoint activation. Breast Cancer Res 14: R60, 2012.

31. Chen Z, Gao H, Dong Z, Shen Y, Wang Z, Wei W, Yi J, Wang R, $\mathrm{Wu} \mathrm{N}$ and Jin S: NRP1 regulates radiation-induced EMT via TGF- $\beta /$ Smad signaling in lung adenocarcinoma cells. Int J Radiat Biol 96: 1281-1295, 2020.

32. Vanveldhuizen PJ,Zulfiqar M, Banerjee S, Cherian R, Saxena NK, Rabe A, Thrasher JB and Banerjee SK: Differential expression of neuropilin-1 in malignant and benign prostatic stromal tissue. Oncol Rep 10: 1067-1071, 2003.

33. Pawlik TM and Keyomarsi K: Role of cell cycle in mediating sensitivity to radiotherapy. Int J Radiat Oncol Biol Phys 59: 928-942, 2004.

This work is licensed under a Creative Commons Attribution-NonCommercial-NoDerivatives 4.0 International (CC BY-NC-ND 4.0) License. 